\title{
Severe Hyperphosphatemia and Hypocalcemia Following Sodium Phosphate Bowel Preparation: A Forgotten Menace
}

A 74-year-old woman was scheduled for colonoscopy due to positive fecal occult blood. On admission, her serum levels of creatinine, adjusted calcium, and phosphate were $113 \mu \mathrm{mol} / \mathrm{l}, 2.24 \mathrm{mmol} / \mathrm{l}$, and $1.17 \mathrm{mmol} / \mathrm{l}$, respectively. She received $90 \mathrm{ml}$ of oral Fleet Phospho-Soda (C.B. Fleet Co. Inc., Lynchburg, Virginia, USA), from which she developed profuse diarrhea. Six hours later, she complained of facial and limb numbness, and appeared drowsy. Her serum phosphate level had risen to $7.29 \mathrm{mmol} / \mathrm{l}$ and her calcium level had fallen to $1.82 \mathrm{mmol} / \mathrm{l}$. During the next hour, muscle cramps and tetany developed over her lower limbs, trunk, and face, with a positive Chvostek's sign. Intravenous administration of $9.0 \mathrm{mmol}$ (40 ml 10\%) calcium gluconate was carried out over $6 \mathrm{~h}$, resulting in resolution of her tetany, while the numbness persisted over the distal limbs. Further infusions were required over the next $17 \mathrm{~h}$ to restore the calcium level to $2.32 \mathrm{mmol} / \mathrm{l}$ (Figure 1). Extensive investigations excluded a secondary cause of the electrolyte disturbance.

Most complications of sodium phosphate bowel preparation are the result of hyperphosphatemia after rapid phosphate absorption and subsequent binding to serum calcium, causing secondary hypocaltotaling $24.75 \mathrm{mmol}$ calcium gluconate

cemia [1]. Patients usually present 6$12 \mathrm{~h}$ after ingestion, with abdominal pain, vomiting, dizziness, muscle cramping, or seizures [2]. Other associated electrolyte disturbances include hypokalemia, hypernatremia, and metabolic acidosis, with increased anion gap [3]. Excessive diarrhea can lead to significant potassium and bicarbonate loss, contributing to hypokalemia and metabolic acidosis [2]. Hypernatremia is secondary to intestinal absorption of sodium from Phospho-Soda, dehydration, and colonic shifting between sodium and potassium.

Factors exacerbating hyperphosphatemia are old age, impaired renal function with reduced phosphate clearance, dehydration, bowel immotility, and repeated dosing. Symptomatic hyperphosphatemia and hypocalcemia are very uncommon in patients with normal renal function [4]. The aims of treatment are to reduce phosphate absorption by oral phosphate binders (calcium acetate or Alusorb), to increase phosphate clearance, and to correct dehydration and electrolyte disturbances. Care must be taken when giving calcium supplement, as renal calcium-phosphate precipitation may further deteriorate renal function [2].

This unusual case is a dramatic reminder that patients with normal renal function

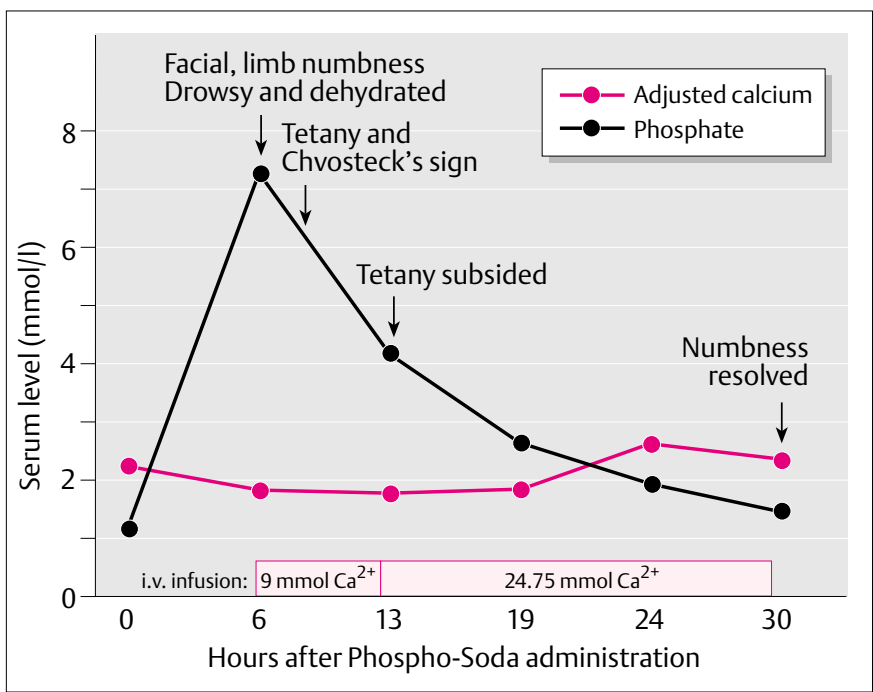

may rapidly develop symptomatic hypocalcemia and hyperphosphatemia after a single dose of oral Phospho-Soda.

K. K. Ma, C. S. H. Ng, L. M. Mui, K. C. Chan, E. K. W. Ng, S. C. S. Chung

Dept. of Surgery, Chinese University of Hong Kong, Prince of Wales Hospital, Sha Tin, New Territories, Hong Kong

\section{References}

${ }^{1}$ Boivin MA, Kahn SR. Symptomatic hypocalcemia from oral sodium phosphate: a report of two cases. Am J Gastroenterol 1998; 93: 2577-2579

2 Tan HL, Liew QY, Loo S et al. Severe hyperphosphataemia and associated electrolyte and metabolic derangement following the administration of sodium phosphate for bowel preparation. Anaesthesia 2002; 57: $478-483$

${ }^{3}$ Kirschbaum B. The acidosis of exogenous phosphate intoxication. Arch Intern Med 1998; 158: 405-408

${ }^{4}$ Lieberman DA, Ghormley J, Flora K. Effect of oral sodium phosphate colon preparation on serum electrolytes in patients with normal serum creatinine. Gastrointest Endosc 1996; 43: 467-469

\section{Corresponding Author}

\section{S. S. C. Chung, M.D.}

Division of Upper Gastrointestinal Surgery Department of Surgery

The Chinese University of Hong Kong Sha Tin, NT

Hong Kong

Fax: $\quad+852-2635-0075$

E-mail: sydneychung@cuhk.edu.hk 